\title{
Planimetría Monumental de los Caudillos del Reino de Jaén en Santisteban del Puerto
}

\section{Planimetry of the Monumental of Jaén Kingdom’s “Caudillos” Located in Santisteban del Puerto}

\author{
Antonio Sánchez-González \\ antonio.sanchez@dhis2.uhu.es @ http://orcid.org/0000-0001-5025-455X \\ Departamento de Historia, Geografía y Antropología. \\ Facultad de Humanidades. Universidad de Huelva. \\ Avda. Tres de Marzo, s/n. 21007 - Huelva.
}

\section{INFO ARTÍCULO}

Recibido: $13-2-2020$

Revisado: 3-5-2020

Aceptado: 22-5-2020

\section{PALABRAS CLAVE}

Planimetría monumental

Santisteban del Puerto

Castillo de San Esteban

Palacio ducal

Convento de San Francisco

Caudillos del reino de Jaén

Archivo Ducal de Medinaceli

\section{KEYWORDS}

Monument planimetry

Santisteban del Puerto

San Esteban Castle

Ducal palace

Convent of San Francisco

Caudillos of the Kingdom of Jaén

Ducal Archive of Medinaceli

\section{RESUMEN}

En el Archivo Ducal de Medinaceli se custodia una interesante colección de mapas y planos, no hace mucho catalogada por un equipo de especialistas como colofón de la ejecución de un proyecto de investigación I+D. En la colección, hay una serie de planos de la Casa de Santisteban del Puerto, caudillos mayores del reino de Jaén. Aquí profundizamos en los de aquellos inmuebles más emblemáticos de esta villa jiennense, como son su castillo de San Esteban, el palacio ducal y el convento de San Francisco.

Nuestra investigación se sustenta en una metodología descriptiva sobre las principales características tipológicas urbano-planimétricas de las ciudades históricas, como es el caso de Santisteban del Puerto. Y su resultado no solo proporciona la oportunidad para una reflexión sobre el valor del dibujo en el mundo de la arquitectura, sino que rectifica algunas imprecisiones del catálogo para contribuir a un mejor conocimiento de esta planimetría artística. Tienen, además, estos planos el atractivo de ser de monumentos que ya han desaparecido. 


\section{INTRODUCCIÓN}

El Archivo Ducal de Medinaceli (ADM) posee una rica colección cartográfica en su sección de "Mapas y Planos", creada a partir de 1890 por el archivero Antonio Paz y Mélia en la que fue su sede madrileña, el antiguo palacio que los duques tenían en el Paseo del Prado (Paz y Mélia, 1915). A mediados del siglo XX apenas se habían recopilado varias decenas de ejemplares, número que fue progresivamente aumentando con los aportes realizados por los sucesivos archiveros de la Casa Ducal hasta nuestros días. Así hoy el número de mapas y planos de la colección se aproxima al millar y, en su mayor parte, ha sido recientemente ampliada y catalogada por el equipo de investigación del Proyecto I+D de excelencia del Ministerio de Economía y Competitividad HAR201341500-P, cuyos resultados editó la Universidad de Huelva no hace mucho (Sánchez González, 2017 a y b).

Obviamente todo este amplio material iconográfico procede de los aportes documentales de los muchos archivos incorporados al Ducal de Medinaceli a través de las agregaciones de los distintos y numerosos estados señoriales y Casas nobiliarias vinculadas a los Medinaceli con el paso de los siglos (Sánchez González, 1997). Por resaltar aquí algunas de las más significativas, y refiriéndonos solo a Andalucía, traemos a colación las posesiones de estados señoriales tales como el ducado de Alcalá de los Gazules, marquesados de Tarifa y Alcalá de la Alameda y condados de El Puerto de Santa María, Los Molares y Castellar -en el reino de Sevilla-, marquesados de Priego y de Comares - en el reino de Córdoba-, o el condado y ducado de Santisteban del Puerto, marquesado de Solera y posesiones próximas a úbeda de los marqueses de Camarasa como Sabiote -en el Santo reino de Jaén-.

Actualmente la colección, en lo que se refiere a las piezas que aquí tratamos, se encuentra ubicada en la sede toledana del Archivo de la Fundación propietaria, el Palacio Tavera, antiguo Hospital de San Juan Bautista. Otra parcela menor de la colección permanece en la Casa de Pilatos de Sevilla.

De entre este valioso material, este artículo pretende identificar categóricamente la planimetría artística de diversos inmuebles radicados en la villa jiennense de Santisteban del Puerto, cabecera del antiguo condado y después ducado del mismo nombre, por quienes desde la Edad Media ejercieron el cargo de Caudillos mayores del reino y obispado de Jaén, del linaje Benavides¹.

Nuestro objetivo es corregir algunas imprecisiones cometidas en aquel catálogo, así como profundizar en determinados aspectos de dichos planos que contribuyen a un mejor conocimiento de los inmuebles representados en la planimetría estudiada.

Para ello, hemos seguido la metodología seguida en trabajos de cartografía urbana de especialistas como J. Calatrava y M. Ruiz (2005) para la ciudad de Granada, de J. Ortega Vidal (2010) sobre Madrid, de J. Burgueño (2001) sobre poblaciones de la provincia de Lérida, del propio Burgueño y Gras (2014) sobre la Cataluña señorial, de M. Galera (1998) sobre ciudades europeas del siglo XVI, de R. Kagan (1986 y 1992) y de J. Hardoy (1991) de ciudades del mundo hispánico, o de Á. Gámiz sobre ciudades dibujadas a vista de pájaro (1999) y otras vistas españolas (2010). De ese modo, los planos jiennenses aquí tratados e interpretados convenientemente desvelan determinados aspectos hasta ahora desconocidos de algunos inmuebles de la villa de Santisteban del Puerto.

Conocidas ya las generalidades acerca de la colección en su conjunto ${ }^{2}$, a la vez que nuestro propósito con este trabajo, nos centramos seguidamente en el argumento del mismo empezando por determinar quiénes eran los caudillos del reino de Jaén, para centrarnos después en aquellos caudillos y señores de Santisteban del Puerto que encargaron los planos de referencia, a los que nos dedicamos particularmente en los sucesivos epígrafes.

\section{LOS CAUDILLOS DEL SANTO REINO}

El oficio de "Caudillo mayor y frontero del reino de Jaén" apareció con la conquista de Al-Andalus por las huestes de Fernando III, primero de Baeza, Úbeda, Martos, etc. y seguidamente de Jaén y su tierra, siendo un cargo militar que lideraba los concejos y pendones de aquel reino.

1. Un estudio detallado de esta casa nobiliaria y sus estados jiennenses es el de Sánchez González, 2015.

2. Más datos en Sánchez González, 2017b. 
Su primer titular — por nombramiento del propio rey Santo- fue Lope de Haro el Chico, hijo del conde y señor de Vizcaya Lope Díaz de Haro y, luego, el caballero Tello Alfonso de Meneses, Señor de Meneses, Tiedra, Montealegre, Grajal de Campos, Alba de Liste, San Román y Villagarcía de Campos, que asistió en 1297 a la batalla de Arjona (Salazar de Mendoza, 1618, p.161-164). Por su parte, todo hace indicar que, con Alfonso $X$, fueron los "caudillos de frontera" quienes se ocuparon de la defensa del reino de Jaén (caso entre otros de Día Sánchez de Fines, que lo ocupó durante dos etapas distintas (Vázquez Campos, 2000 y 2006). Ya en tiempos de Alfonso XI reaparece la denominación de caudillo mayor del reino de Jaén en Enrique Enríquez el Mozo, ricohombre de Castilla y justicia mayor de la Casa del rey, que en 1340 dirigió la vanguardia en la batalla del Salado. Y tras él vinieron a ocupar este cargo Men Rodríguez de Benavides —con los monarcas Pedro I y Enrique II-, como también su hijo Gómez Méndez de Benavides —con Juan I y Enrique III-, quien lo recuperó para su estirpe tras un paréntesis en que lo fue el comendador mayor de Calatrava, Gutierre Díaz de Sandoval (Toral y Fernández de Peñaranda, 1984).

En cuanto a las competencias del oficio, el Caudillo mayor del reino de Jaén era el capitán y guía del ejército formado por las tropas de todas las ciudades y villas del obispado jiennense. En palabras de Pedro Salazar de Mendoza $(1618,161)$ "era el Capitán General de aquel reyno en el tiempo que fue frontera de los moros de Andalucía y reyno de Granada".

Ya Alfonso X aleccionó en el Espéculo acerca de la conveniencia de hacer la guerra "ayuntados" y de la importancia del caudillaje. Y en el título V del libro III de dicha obra legislativa alfonsí ("Cómmo se deuen acavdillar..."), se apuntan algunas cuestiones de interés, sobre todo en las leyes primera ("Qué pro viene del buen acavdillamiento et qué danno si non fuere bien guardado"), sexta - acerca de la necesaria obediencia al caudillo en las huestes y cabalgadas - y décima — sobre las penas a aplicar a quien deshonrase, hiriere 0 matase a su caudillo- (véase MacDonald, 1990, p. 451-455).

En parecidos términos se expresa el mismo rey Sabio en las Partidas, refiriéndose al caudillo mayor como "maestro de la caballería, guía y capitán de los exércitos", y tratando aspectos interesantes como las condiciones que debe reunir el candidato para su elección, que resume en "esfuerço, maestría e seso", principalmente este último, la inteligencia y el conocimiento del oficio ${ }^{3}$. Por su parte, la ley XI del título XVIII de la Partida cuarta complementa las funciones ya referidas del caudillo, en lo que afecta a sus cometidos judiciales.

Trata además Salazar de Mendoza en su clásica obra sobre las dignidades seglares de Castilla y León, siguiendo en este caso el Nobiliario de Fernán Mexía (1492, cap. 93), de la honorabilidad de este oficio argumentando que "con el cabdillo del Obispo de Jaén se han de juntar las ciudades del Obispado en tiempo de las guerras ó rebatos de moros. E es aquel al qual es encomendada hueste, ú de cabdillar la gente de la guerra, é de alguna provincia...", añadiendo que quien tal cargo ocupa "...ha de entender en facer los alardes, é asímesmo en facer caballeros nuevos de premia; asímesmo de sacar por ancianía algunos de caballeros de premia. É á otras prerrogativas". También precisa otras virtudes que deben adornar al caudillo mayor diciendo que "...ha de ser muy esforzado, valeroso, noble, magnífico, notable, estrenuo y claro" (Salazar de Mendoza, 1618, p. 161).

El hecho es que estos Benavides, señores de Santisteban del Puerto, que en vida habían ganado sucesivamente la confianza de los monarcas castellanos para ocupar el cargo y oficio de caudillo mayor del obispado de Jaén, uno tras otro, siguieron ostentando el oficio de manera vitalicia a lo largo de la Edad Media (Sánchez González , 2015, p. 30-34) y, con el tiempo - a partir de los Reyes Católicos4_-, llegarían a poseerlo como dignidad vitalicia ${ }^{5}$ (Vidania, 16966).

3. Abunda en esto la Partida IV, título XXIII, ley IV (véase Sánchez-Arcilla Bernal, 2004, p. 662).

4. Aún en tiempos de Felipe IV, este monarca nombra caudillo de Jaén al entonces VII Conde de Santisteban Francisco de Benavides, así como a su hijo y sucesor Diego, lo que venía a ser un reconocimiento a la transmisión del oficio, ya como mera dignidad, a los titulares de la Casa (véase ADM, Santisteban, 13-29).

5. Una dignidad que quedó asociada al título de Santisteban del Puerto.

6. Un ejemplar de este memorial en ADM, Archivo Histórico, 224-5 (h). 


\section{SANTISTEBAN DEL PUERTO, CABECERA DE UN ESTADO SEÑORIAL}

Santisteban del Puerto - o San Esteban de Eznatoraf, como también se le conoció originariamente- era un enclave estratégico en la frontera suroriental castellana con el reino nazarí pues controlaba el puerto de Montizón, paso obligado de comunicación de Al-Andalus con Castilla y Levante, desde el elevado cerro amesetado que le daba nombre al lugar donde se erguía su castillo-ciudadela (Mercado Egea, 1973 y 1997).

Tras la conquista definitiva del territorio al poder musulmán en 1226 por las huestes de Fernando III quien parcialmente la pobló-, pasó a ser aldea de Úbeda con Alfonso X en 12547, de cuya ciudad dependió durante algún tiempo. Esta situación cambia cuando, para poblarla mejor, el propio Rey Sabio concedió a sus moradores la merced de que el lugar tuviese consideración de "villa real" y los derechos de su portazgo y almotacenazgo por privilegio rodado otorgado en Sevilla el 31 de marzo de $1261^{8}$. Luego Sancho IV le confirmaría esa situación de realengo a Santisteban por otro privilegio rodado fechado en Burgos el 15 de marzo de $1285^{9}$, de nuevo confirmado por Fernando IV diez años más tarde ${ }^{10}$. Temporalmente, en tiempos de este monarca, la villa pasó a la jurisdicción de la orden de Calatrava por privilegio otorgado en Valladolid el 2 de marzo de 130011, una posesión muy corta si tenemos en cuenta que solo tres años después el rey refrendaba a la población todos sus privilegios ${ }^{12}$, que se ratificaban en 1313 durante la minoría de Alfonso XI ${ }^{13}$.

Desde entonces continuó Santisteban del Puerto como territorio realengo hasta que, tras la victoria de Montiel de 1369, el nuevo monarca entronizado, Enrique II de Trastamara, recompensó a su colaborador Men Rodríguez de Benavides concediéndole la villa de Santisteban del Puerto con sus aldeas y términos, en señorío perpetuo para sí y sus sucesores, por privilegio otorgado en las cortes de Toro el 25 de septiembre de 1371, en agradecimiento a los servicios prestados ${ }^{14}$. Esta merced era confirmada por el propio rey cinco años después, al tiempo que le concedía mayorazgo con ese señorío y demás bienes para su descendencia ${ }^{15}$.

El dominio santistebeño fue elevado a condado en 1473 por el rey Enrique IV ${ }^{16}$, con unos límites territoriales plenamente configurados. Un estado formado por la propia villa cabecera de Santisteban del Puerto y por los lugares anexos de Castellar de Santisteban - con el entonces despoblado de Espinosa y la dehesa de Montizón- por el este, y Navas de San Esteban (desde principios del siglo XIX, denominada Navas de San Juan) con la antigua Aldeaquemada, por el oeste, hasta Vilches y Arquillos, aldeas de Baeza (Sánchez González, 2015, p. 45-46) ${ }^{17}$.

Fue muy dilatada la etapa condal de este dominio jiennense de los Benavides, caudillos de aquel reino, pues aquel estado señorial no adquiriría hasta mucho más tarde la condición de ducado, cuando rey Felipe $\checkmark$ les hace tal merced en 1739. Y como ducado de Santisteban del Puerto se integró en la Casa Ducal de Medinaceli a principios del siglo XIX.

7. ADM, Privilegios Rodados, $n^{\circ} 13$ (doc. inserto) y Archivo Histórico Municipal de Úbeda (AHMU), carpeta 5, doc. 4 (doc. inserto).

8. ADM, Privilegios Rodados, n 9. Documento transcrito en Sánchez González, 2015, p. 247-250.

9. ADM, Privilegios Rodados, $\mathrm{n}^{\circ} 13$ (doc. inserto).

10. ADM, Privilegios Rodados, $n^{\circ} 13$ (Valladolid, 3 agosto 1295): Fernando IV confirma la merced que el rey Sancho IV había hecho en 1285 a los pobladores de San Esteban de Eznatoraf de que fuese villa, de su portazgo, almotacenazgo y roda del puerto de Montizón, como la tenía en el puerto del Muradal, y para que pudiesen poblar La Bastida, guardando a su costa el puerto. Cfr. Sánchez González, 2009, p. 231.

11. ADM, Privilegios Rodados, $n^{\circ} 15$ (con fecha incompleta) y Archivo Histórico Nacional (AHN), Órdenes Militares (Calatrava), Documentos reales, carpeta 427, n 153: Fernando IV da a la orden de Calatrava y a su maestre García López la villa de Santisteban del Puerto con los castillos de su término, sus tercias y las tercias de Zorita, Sabiote, el Collado y Cogolludo, a cambio del monasterio del Santo Ángel de Ursaria, situado en Apulia. Cfr. Sánchez González, 2009, 232.

12. AHN, Órdenes Militares (Calatrava), Documentos reales, carpeta 427, $n^{\circ} 158$.

13. ADM, Santisteban, 1-29 (carta abierta. Villa Real, 22 noviembre, 1313).

14. ADM, Privilegios Rodados, $n^{\circ} 55$ (original) y 59 (doc. inserto). Documento transcrito en Sánchez González, 2015, 255-259. Cfr. Sánchez, A. 2009, p. 248 y 250.

15. ADM, Privilegios Rodados, nº 59 (A.-original). Segovia, 26 julio 1376. Documento transcrito en Sánchez González, 2015, p. $260-264$. Cfr. Sánchez, 2009, p. 250.

16. ADM, Archivo Histórico (Títulos), caja 3 n 4R (A.-original). Santa María de Nieva, 21 septiembre 1473. Documento transcrito en Sánchez González, 2015, p. 265-266.

17. Muy próximos al estado de Santisteban, por el suroeste, se hallaban los señoríos agregados, también jiennenses, de Ibros y Espelúy. Y más al sur, el marquesado de Solera, título que ostentaba el heredero de la Casa de Santisteban del Puerto (Sánchez González, 2016). 


\section{METODOLOGÍA}

Los planos objeto de estudio en este trabajo son concretamente seis, que reproducen inmuebles emblemáticos de la villa de Santisteban del Puerto, como son su castillo-fortaleza, el palacio señorial de los condes y duques del lugar, la cárcel de la población y el convento de San Francisco.

Esta planimetría tiene la particularidad de ser auténtica reliquia iconográfica de edificios que ya han desaparecido, lo que agiganta su importancia.

Y como el catálogo reciente realizado sobre esta planimetría (Sánchez González, 2017a, p. 405-40818), aun siendo bastante valioso, adolece de alguna imprecisión hemos pretendido subsanar aquí tales deficiencias. De ahí que ahora realicemos la mejora pertinente a la par que profundizamos en el estudio del material partiendo de la información que transmiten los propios planos en sus respectivas leyendas y a través de la localización de documentación adicional en el propio Archivo Ducal que nos ha permitido despejar algunas cuestiones no resueltas anteriormente.

Además, hemos cotejado dicha documentación con la existente en otros depósitos como el Archivo Municipal de Santisteban del Puerto, Archivo Histórico Provincial de Jaén, Archivo de la Real Chancillería de Granada y Archivo Histórico Nacional, en este último caso a través del portal PARES de Archivos españoles en red.

Realizado ese trabajo heurístico de localización de fuentes documentales, solo cabía añadir la información obtenida para mejor interpretación del material planimétrico.

En concreto, hemos consultado algunos fondos específicos como la documentación relativa a la titularidad y dominio de esos inmuebles ${ }^{19}$, algunos informes de los archiveros de la Casa de Santisteban sobre el castillo y el palacio de los señores ${ }^{20}$, así como la serie completa de documentos del Convento de San Francisco ${ }^{21}$ del propio Archivo señorial. Complementariamente, hemos manejado algunos informes de intervención arqueológica de zonas afectadas y, mediante la cartografía urbana, hemos intentado delimitar los enclaves históricos de algunos edificios.

\section{LA PLANIMETRÍA MONUMENTAL DE SANTISTEBAN DEL PUERTO}

\subsection{Plano del Castillo-fortaleza}

En el reino de Jaén, desde el siglo XIV, quedaron afincados los Benavides por mucho tiempo en torno a la villa de Santisteban del Puerto y su comarca, dejando paulatinamente sus iniciales posesiones en el reino de León. Y con toda seguridad, la morada y corte señorial en la ciudad jiennense, al menos a lo largo de toda la Edad Media, se estableció en el castillo de San Esteban que, por su gran extensión, parecía más un alcázar o ciudadela, fortaleza que se levantaba sobre el cerro amesetado del mismo nombre, un enclave importante en la estrategia defensiva del estado señorial pues desde allí se vigilaba y controlaba todo el puerto de Montizón por el que se comunicaba Andalucía con la meseta castellana y el levante peninsular ${ }^{22}$ (figura 1).

Y aunque el castillo se fue deteriorando con el paso de los siglos, de aquella antigua fortaleza de Santisteban del Puerto se conserva entre la colección Medinaceli un plano, realizado en torno a 1780, cuando era titular del estado doña Joaquina María de Benavides y Pacheco (1746-1805), III Duquesa de Santisteban del Puerto, esposa a partir de 1789 de don Luis María Fernández de Córdoba y Gonzaga (1749-1806), futuro XIII Duque de Medinaceli, con quienes se unieron estas dos importantes casas ducales. La traza corresponde a Alonso García y lleva por título "Plan del Palacio echo en la Billa de Santiestevan, y su nueba distrivución como está anotado; que su costo adciende a diez mil y quinientos reales [de] vellón" 23.

18. Posteriormente, a nivel divulgativo, se reprodujeron estos planos en la revista local La Guaría, 4 (abril 2019), p. 54-63.

19. ADM, Santisteban, leg. 1 nos 1-37 y leg. 13 nos 29 y 32.

20. ADM, Santisteban, leg. 39 nos 1 y 2, leg. 40 nos 1 y 2 , y leg. $45 n^{\circ} 24$.

21. ADM, Santisteban, leg. 29 nos 30, 32 y 36, leg. $41 n^{\circ} 6$ y leg. $44 n^{\circ} 50$.

22. Más datos de este recinto fortificado, desde el período musulmán, en Eslava, J. 1999, p. 141-145.

23. ADM, Mapas y planos, $n^{\circ} 474$. Plano comentado en el citado Catálogo por los profesores A. Sánchez González y T. Falcón Márquez (Sánchez González, 2017a, p. 405-406). 


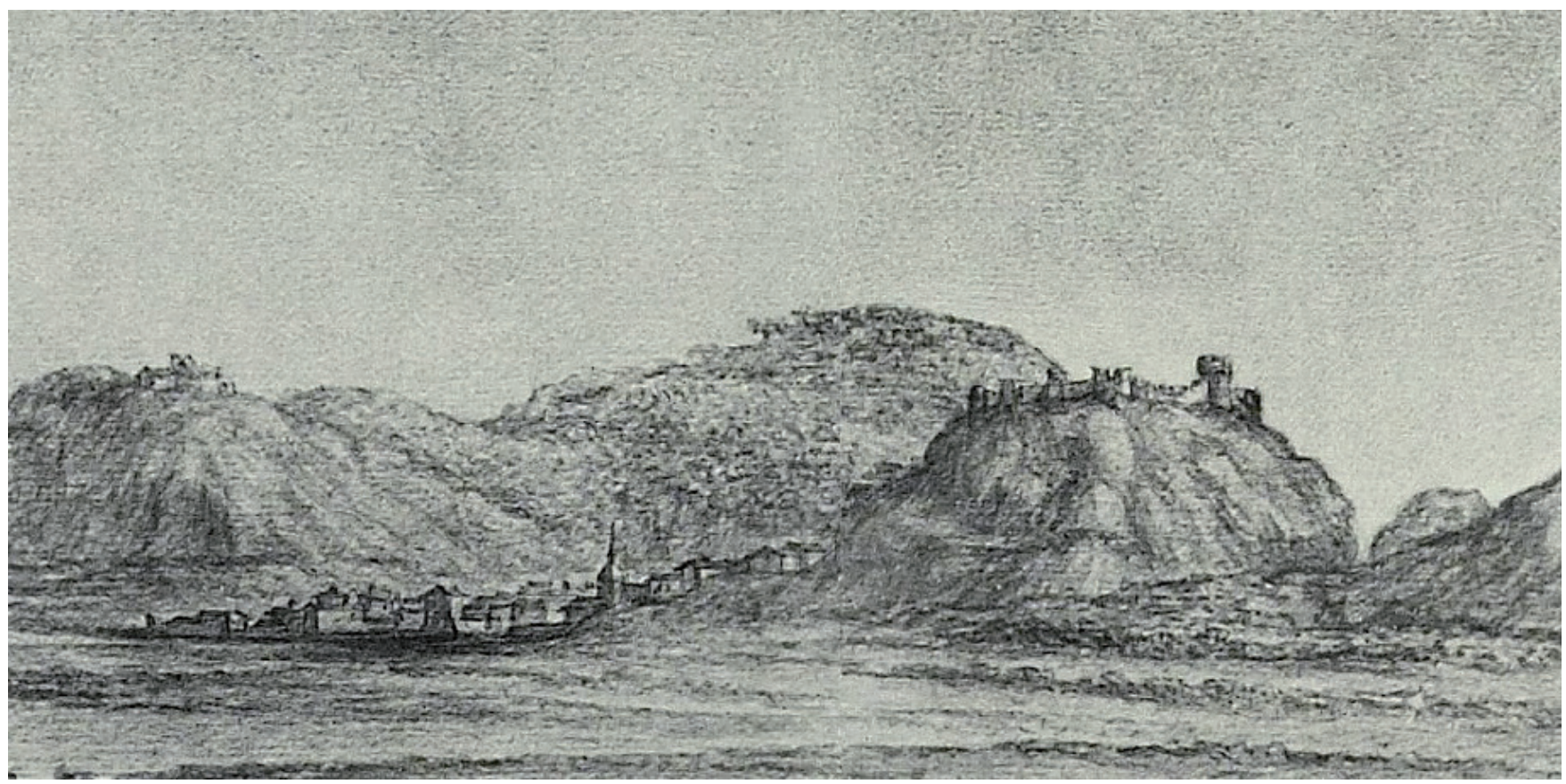

Figura 1. Vista de Santisteban del Puerto, con el castillo sobre el cerro y la villa al pie. Detalle de acuarela de Pier Maria Baldi, 1669. Fuente: Biblioteca Medicea Laurenziana de Florencia. ${ }^{24}$

El plano (figura 2) muestra una fachada del inmueble, en la que se abren dos puertas, por las que se acceden a los dos sectores casi simétricos del edificio que separa un muro interior central: uno está dedicado a la "contaduría del alcalde mayor" y a su vivienda (con zaguán, una alcoba, sala, cocina, etc.) y, el otro, reservado a las dependencias administrativas del castillo (con otro zaguán, sala, dormitorio, cocina, comedor, etc.), quedando el despacho y otra sala en el bajo de un torreón lateral que no lleva remate. Las cuadras y el corral quedan emplazadas en la parte trasera del edificio y todos los vanos son de dintel adovelado.

Esta planta y alzado muestran cómo se hallaba el castillo-palacio en aquella fecha, tras una distribución de espacios proyectada en una reforma cuyo coste ascendía a 10.500 reales de vellón.

Hoy de este castillo solo permanecen restos del torreón norte y determinados vestigios de sus antiguas fortificaciones.

\subsection{Plano del Palacio del Llano}

Obviamente la ubicación de aquel castillo-palacio en lo más alto del cerro de San Esteban, situado a 820 metros de altura, no era lo más recomendable para tener la morada y administración señorial, razón por la que más adelante bajaría para instalarse en la casa-palacio que la familia Benavides, condes por entonces del lugar, levantó sobre la torre del recinto amurallado de la villa que vigilaba la llamada "Puerta del Llano" que daba a la calzada de San Juan (Mercado Egea, 1973, p. 79), en un lateral de la plaza Mayor de la villa cabecera de su estado andaluz ${ }^{25}$.

25. De hecho, se conserva en el Archivo de los duques de Medinaceli una certificación de tres escribanos públicos de Santisteban que en 1717 acreditan que los entonces condes del lugar tienen "y han tenido sus antecesores dos casas palacios, la una dentro de los muros de la villa, que toca a la feligresía de Santa María del Collado, [...] y la otra extramuros de esta villa, que es la que llaman el Palacio de la Guarida [...] en la feligresía de la iglesia parroquial del Señor San Esteban" (ADM, Santisteban, 9-8). 


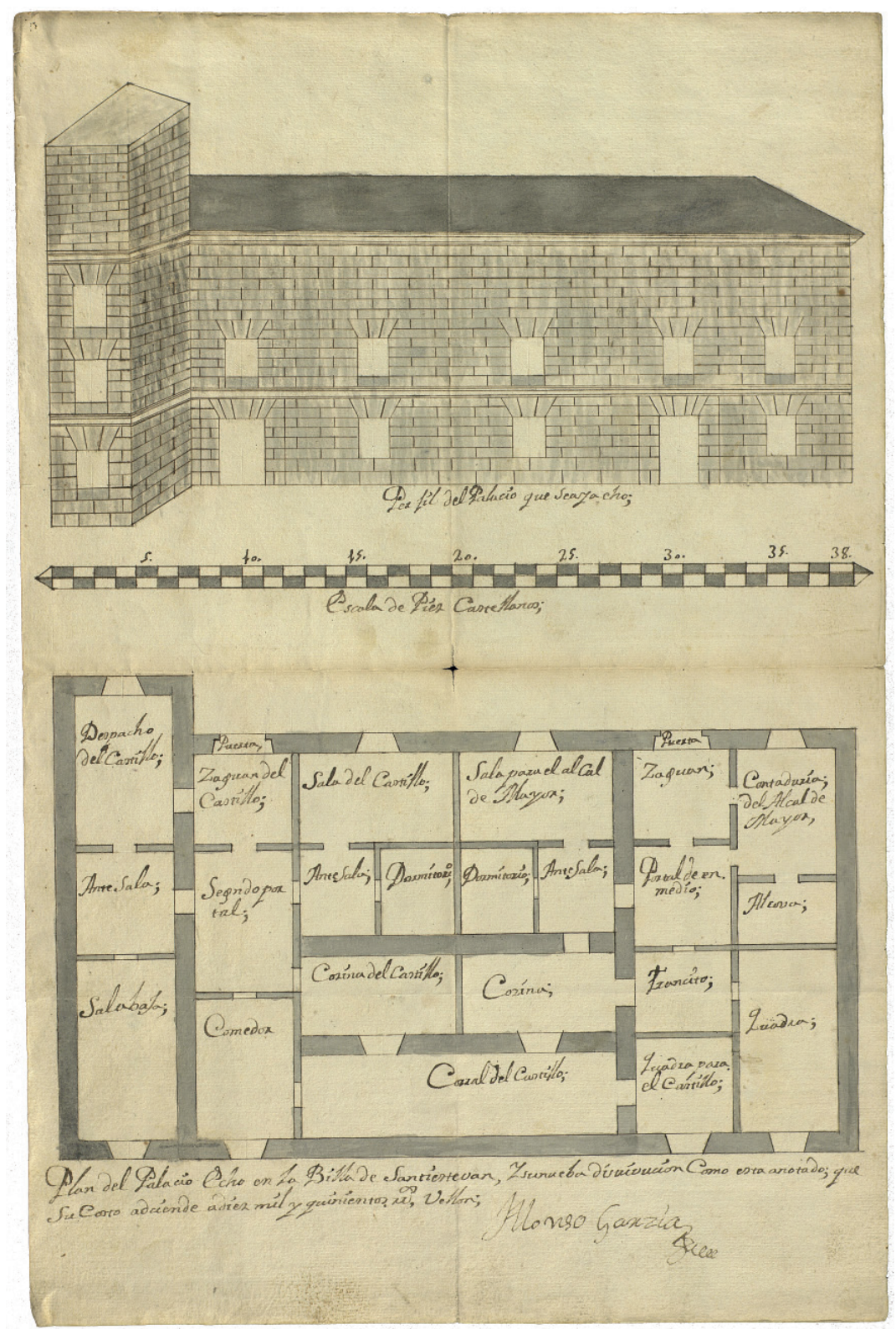

Figura 2. Planta y alzado de la adaptación palaciega del castillo de San Esteban (Siglo XVIII).Fuente: ADM, Mapas y planos, $n^{\circ} 474$.

De este inmueble existe un plano trazado por Antonio Briones ${ }^{26}$ (figura 3), realizado también en torno a 1780 cuando era propietaria del estado y de aquel inmueble la misma doña Joaquina de Benavides. Representa la planta a color y el alzado de la vivienda "con todas sus oficinas" 27 mostrando un edificio de cantería de dos pisos, con planta rectangular, y portada desplazada hacia la izquierda sobre la que se hallaba el balcón. En su interior carece de patio principal. A la izquierda del vestíbulo se hallaba la Contaduría y en el extremo de la derecha un torreón, con cubierta a cuatro aguas, en cuya planta baja había un despacho. Otras dependencias eran la sala principal, un gabinete, varios dormitorios, cocina, horno, un pequeño patio interior, además de las cuadras y cobertizo. En el lateral derecho se ubicaba el jardín, posiblemente en dos niveles, en el que había un cenador y el mirador de ángulo. Al exterior se cerraba por un alto muro.

26. Este mismo Briones realizó un plano, similar en cuanto a su ejecución e igualmente de bella factura, de la casa y molino del Salido en aquella misma comarca del Condado (ADM, Mapas y planos, $\mathrm{n}^{\circ} 482$ ).

27. ADM, Mapas y planos, $n^{\circ} 473$. Plano comentado en el citado Catálogo por los profesores A. Sánchez González y T. Falcón Márquez (Sánchez González, 2017a, p. 405). 


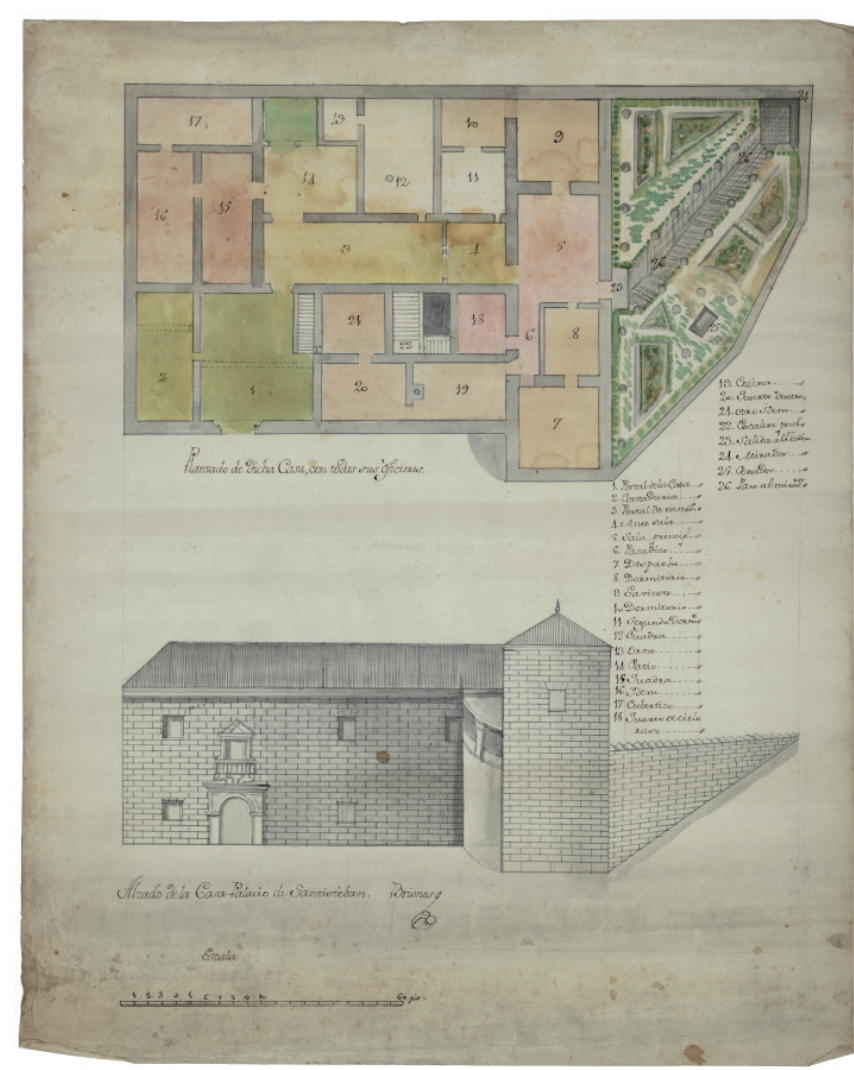

Figura 3. Planta y alzado del palacio ducal de Santisteban del Puerto (Siglo XVIII). Fuente: ADM, Mapas y planos, $\mathrm{n}^{\circ} 473$.

En aquella casa-palacio santistebeña prolongó la Contaduría señorial su existencia hasta que el inmueble fue vendido por los duques de Medinaceli y Santisteban a mediados del siglo XX. Luego el edificio lamentablemente sería demolido durante la década de los 70 del mismo siglo pasado (figura 4).

\subsection{Planos de la cárcel}

El mismo Alonso García que trazó la reforma del castillo a fines del siglo XVIII, por esas mismas fechas (alrededor también de 1780) realizó a escala de 23 pies castellanos [ca. 1:50] otro plano con el proyecto de cárcel, audiencia y vivienda del alguacil de la villa santistebeña ${ }^{28}$.

El proyecto (figura 5) presenta un edificio de planta cuadrada. Tras la portada, ligeramente desplazada hacia la izquierda, se hallaba el "calabozo subte-

28. ADM, Mapas y planos, $n^{\circ} 475$. Plano comentado en el citado Catálogo por los profesores A. Sánchez González y T. Falcón Márquez (Sánchez González, 2017a, p. 406).

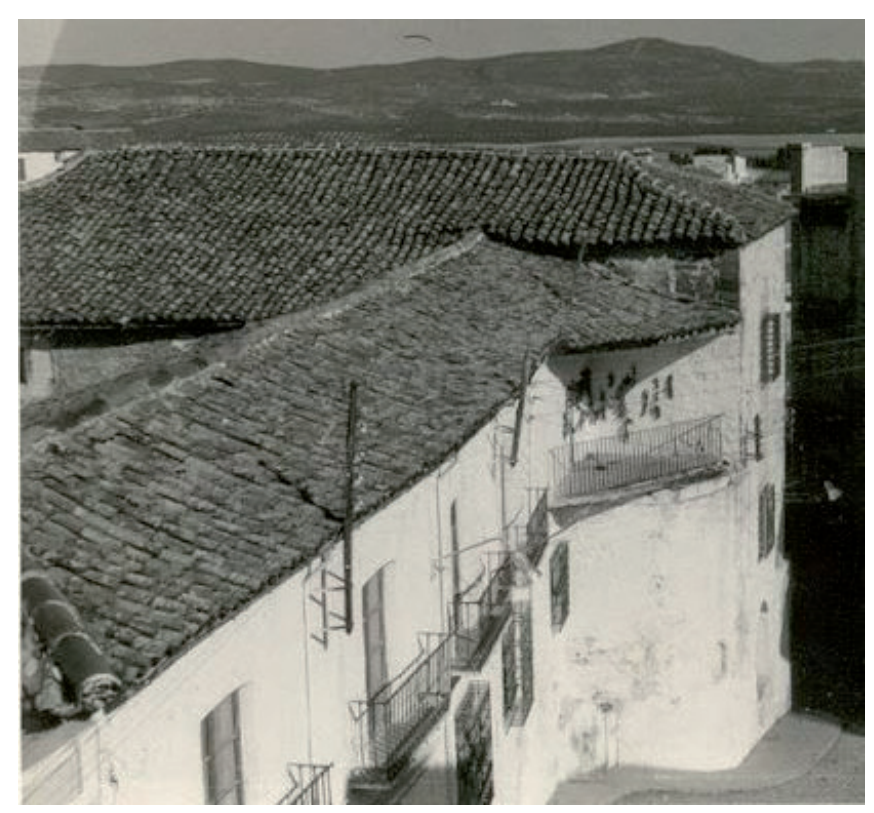

Figura 4. Casa-palacio de los Benavides en Santisteban del Puerto, poco antes de su demolición. Fuente: Fotografía de autor desconocido <http://gabrielsagra. blogspot.com/2014/09/palacio-de-los-duques-de-santisteban.html>

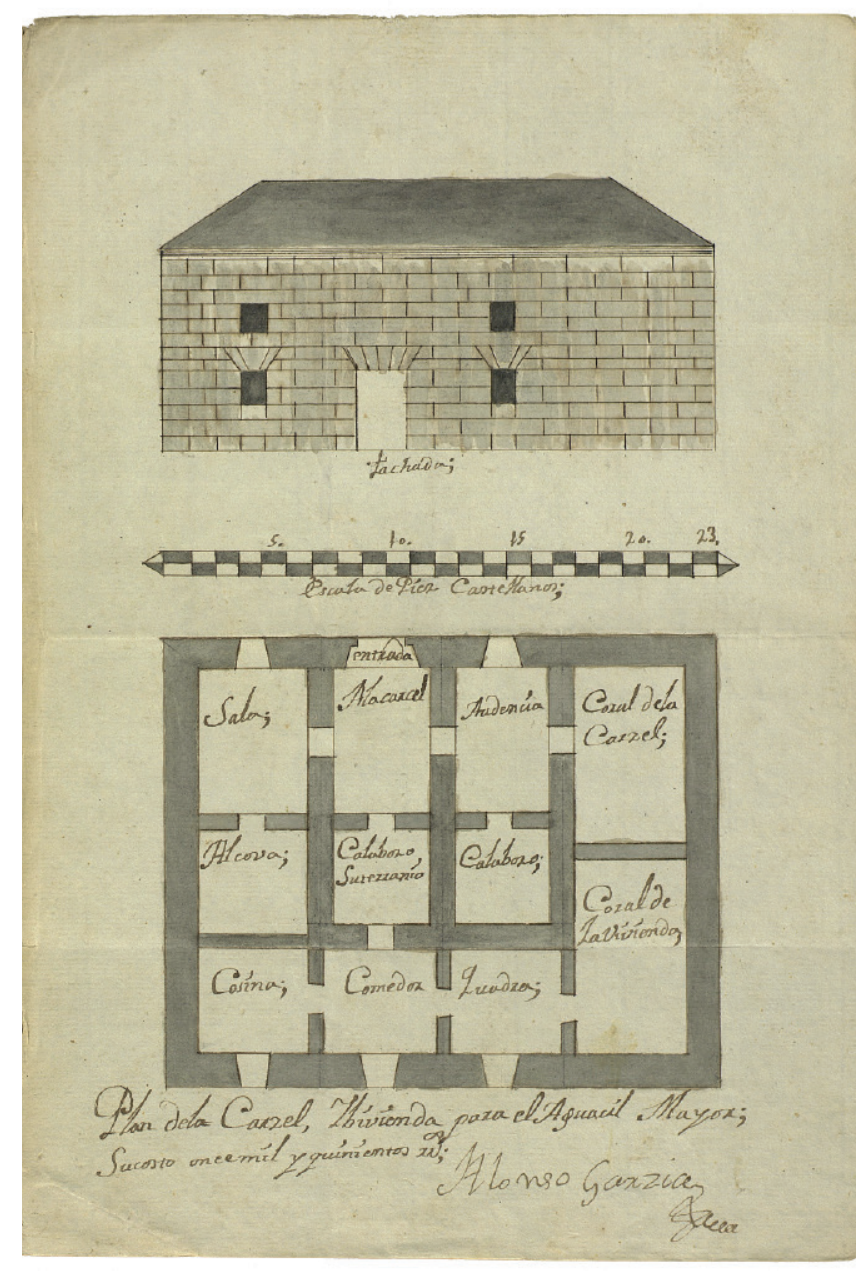

Figura 5. Planta y alzado de la cárcel de Santisteban del Puerto (Siglo XVIII). Planta y alzado de la cárcel de Santisteban del Puerto (Siglo XVIII). 
rráneo" y en la crujía de fachada se ubicaban la audiencia -que también tenía su calabozo-, sala y corral de la cárcel. En la fachada trasera se indica el comedor, la cocina, la cuadra y el corral de la audiencia. Era una obra de cantería, y su alzado repite el mismo esquema que la fachada del palacio del castillo. Este proyecto tenía un coste de 11.500 reales.

No fue ese el único plano de este espacio que se realizó pues el ubetense Diego Rodríguez, que suscribe como "maestro de arquitectura y fiel alarife", en octubre de 1787 trazó a escala de 10 varas castellanas [ca. 1:200] un "Plan de la cárcel, casa y avitación de el Sr. Alcalde Mayor, Alcayde de ella y oficinas correspondientes, mandado a practicar de orden de la Excma. Sra. Duquesa de este estado", la misma doña Joaquina de Benavides $^{29}$ (figura 6). Acompaña al juramento del propio autor rechazando la obra que pretendía realizar en el solar la duquesa de Santisteban "por lo diminuto del espacio" y por riesgo de aluviones del barranco, avalando este proyecto suyo que presupuesta con un importe total de 150.072 reales de vellón.

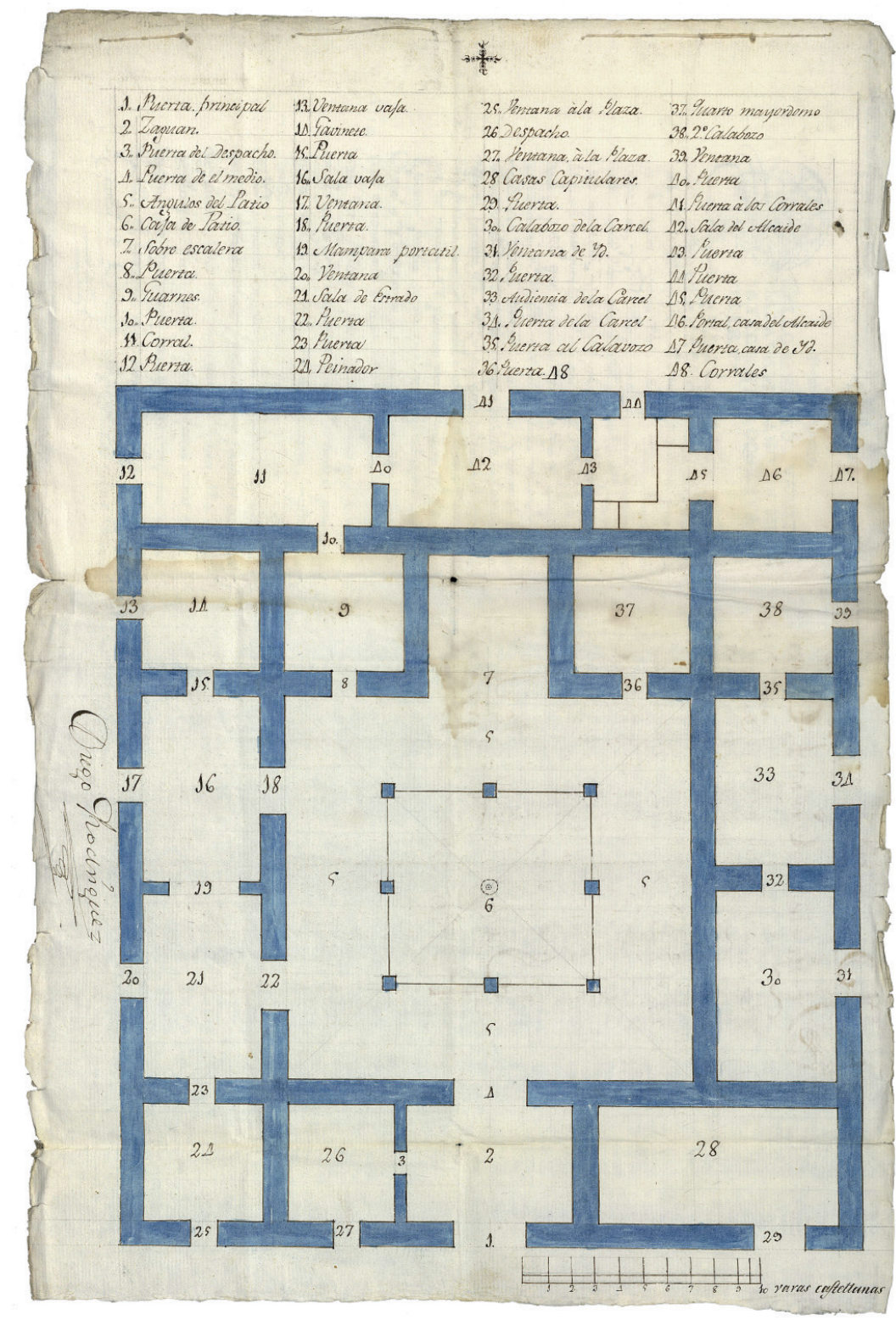

Figura 6. Otra planta de la cárcel de Santisteban del Puerto (Siglo XVIII). Fuente: ADM, Mapas y planos, $n^{\circ} 476$. 
La planta de la cárcel y vivienda del alcaide mayor diseñada por Diego Rodríguez es más espaciosa, diáfana y regular que la que proyectó siete años antes Alonso García. El edificio se organiza en torno a un patio cuadrado, rodeado con galerías de tres pilares en cada frente. En la crujía de fachada principal se ubican las casas capitulares, con acceso independiente y ventanas a la plaza. En el ala derecha está la zona carcelaria, con calabozos y audiencia de la cárcel. En el ala opuesta, a la izquierda, se sitúan el gabinete, sala baja, sala de estrado y peinador. Por último, en la fachada trasera estaba la vivienda del alcaide, su sala y el corral, más guadarnés.

\subsection{Planos del Convento de San Francisco}

Del convento franciscano de la villa, fundado extramuros de ella en los albores del siglo XV por el tercer Señor de Santisteban del Puerto Día Sánchez de Benavides I ${ }^{30}$, se conservan en el Archivo Ducal dos trazas - ambas del siglo XVIII- que representan la planta y el alzado de dos sectores distintos del edificio.

El convento cayó en un progresivo estado de abandono con el paso del tiempo y en el siglo XVIII amenazaba ruina. De ahí estos proyectos de mejoras, además siendo lugar de enterramiento de estos Benavides, condes y duques del lugar ${ }^{31}$.

La primera de estas trazas (figura 7), titulada "Planta del quarto nuebo del convento de San Francisco de Santisteban"32 está rubricada ${ }^{33}$ y hecha, a escala imprecisa, en pies y varas sin determinar. Plantea la construcción de ese "quarto nuevo" para este convento de San Francisco de Santisteban del Puerto, diseñada en planta y alzado. La planta es simple, parcelada en seis estancias rectangulares invertidas prácticamente iguales, que no se identifican en el plano. Y el alzado presenta dos cuerpos con proyección horizontal, articulados con pilastras toscanas superpuestas. La división entre ambos cuerpos se acentúa por una balaustrada ciega corrida. El aparejo mixto proyectado, con basamento y seis refuerzos verticales embutidos de fábrica, y sillares en las zonas intermedias, contrasta con dicha disposición. En el espacio intermedio de la tercera calle por cada lado en el segundo cuerpo, presenta escudos heráldicos. La cubierta a dos aguas sobre un techo adintelado sobre vigas de madera está rematada por seis eleolipas serlianas en el vértice y una en cada extremo de la caída de esas aguas.

La segunda traza conservada (figura 8) se titula "Planta del quarto nuebo del convento de San Francisco de Santisteban. Alzado del quarto por la parte que mira a el norte" y está hecha a escala de 30 tercias [ca. $1: 70]^{34}$. El plano, en este caso, marca el lugar de la iglesia, el patio, la enfermería y otras dependencias conventuales existentes.

El alzado establece las condiciones de la nueva construcción respecto de la crujía a la que iría asociado, y muestra una fachada con dos cuerpos horizontales sin articulación alguna, como corresponde a la arquitectura popular de época barroca, con cubierta a dos aguas y tres guardillas para iluminar un espacio superior que serviría de almacén. Al dorso especifica que "el color amarillo demuestra el edificio que está hecho", es decir, la parte ya edificada, mientras que se identifica en rojo la nueva edificación proyectada en el plano.

30. Fue creado para impulsar la fe en su señorío y como panteón para él y sus descendientes. Al parecer, se iniciaron las obras en 1400 y no concluyeron hasta el tercer cuarto de ese mismo siglo, ya en tiempos de Día Sánchez de Benavides II, V Señor de Santisteban y I Conde de aquel estado. Sabemos que en 1433 se trasladaron varios frailes desde el convento franciscano de Sevilla a este de Santisteban del Puerto, por licencia del ministro de los frailes menores de la provincia de Castilla a Men Rodríguez de Benavides, hijo del fundador (ADM, Santisteban, leg. 29 n³0).

31. Se conservan en el Archivo de los Santisteban un buen número de documentos sobre traslados de restos mortales y enterramientos de los condes, duques y familiares en el panteón que tenían en este convento franciscano (ADM, Santisteban, leg. 3 nos 109, $110,113,117,120,139,141,142,148)$, del que eran estos señores eran patronos y al que hicieron importantes legados (ADM, Santisteban, leg. 29 nos 32 y 36).

32. ADM, Mapas y planos, $n^{\circ}$ 477. Plano comentado en el citado Catálogo por los profesores A. Sánchez González y A. Luque Teruel (Sánchez González, 2017a, p. 407-408).

33. La rúbrica en una esquina del plano Antonio [Divago? (apellido ilegible)].

34. ADM, Mapas y planos, $n^{\circ}$ 478. Plano comentado en el citado Catálogo por los profesores A. Sánchez González y A. Luque Teruel (Sánchez González, 2017a, p. 408). 


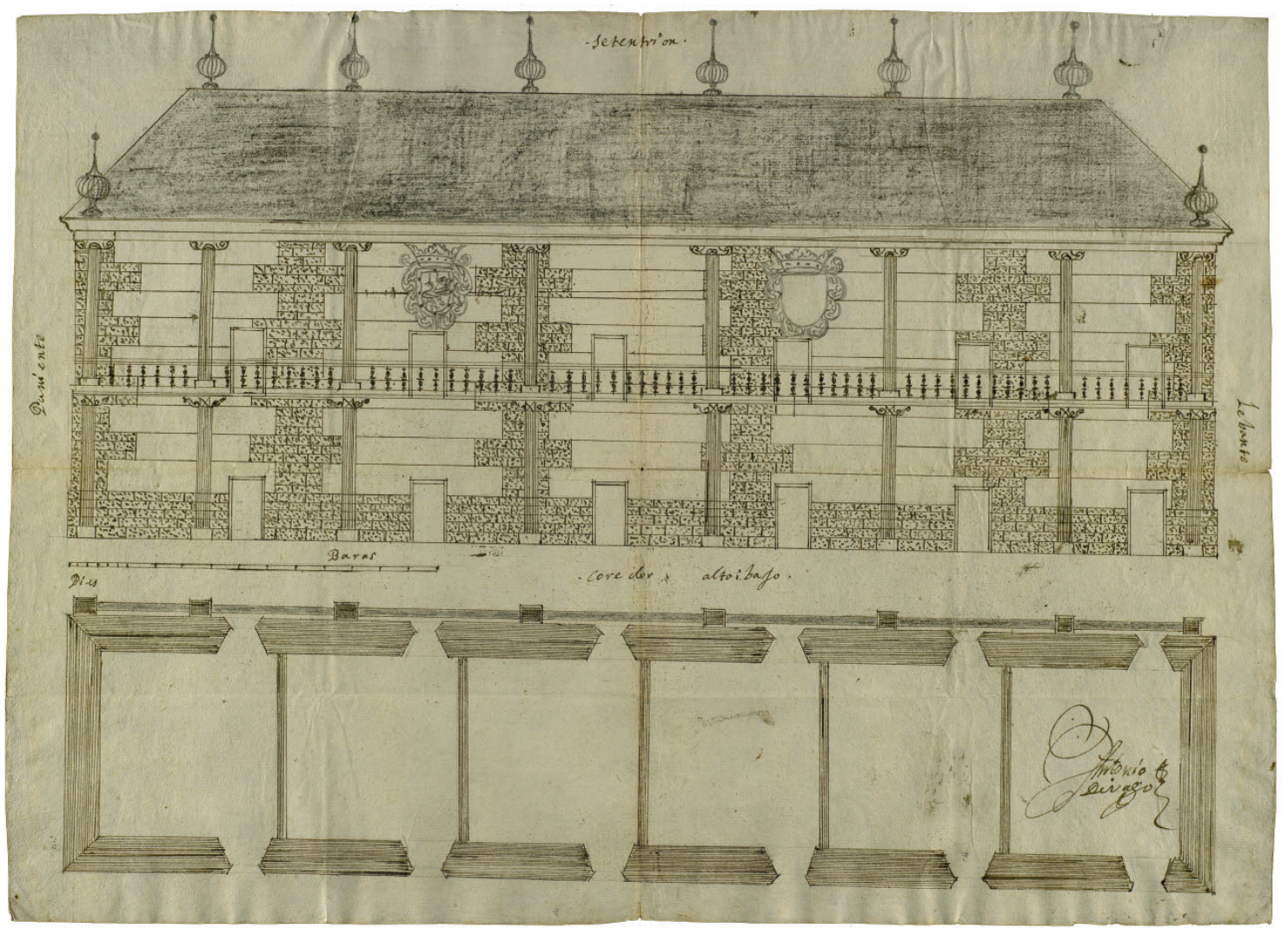

Figura 7. Planta y alzado de la reforma del convento de San Francisco (Siglo XVIII). Fuente: ADM, Mapas y planos, $n^{\circ} 477$.

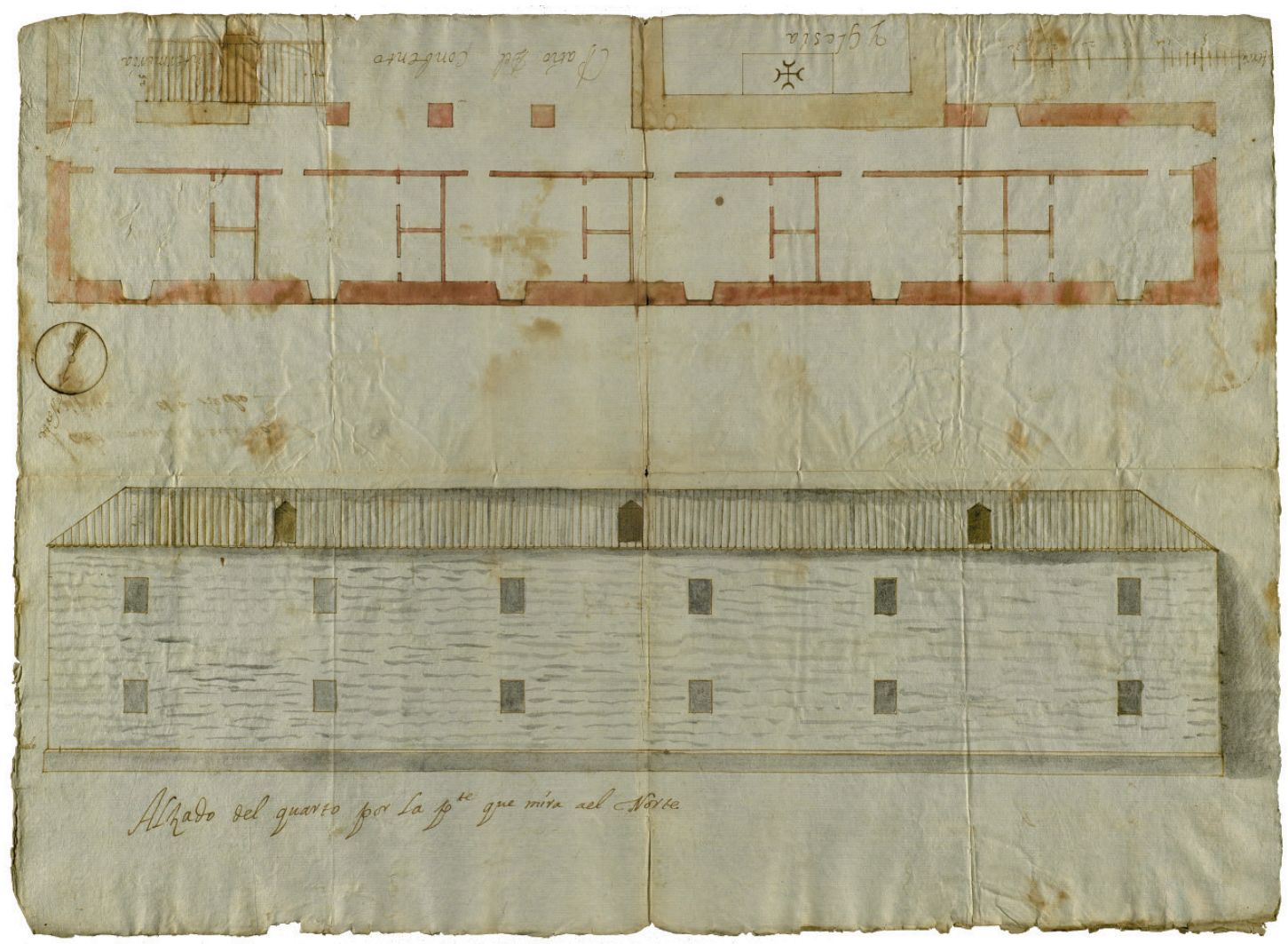

Figura 8. Planta y alzado de otra reforma en el Convento de San Francisco (Siglo XVIII). Fuente: ADM, Mapas y planos, $\mathrm{n}^{\circ} 478$. 
Tal vez tenga relación este diseño con las reformas emprendidas en el convento en 1793 por la duquesa de Santisteban doña Joaquina María de Benavides y Pacheco, si bien parece que las acometidas dicho año afectaron principalmente a la renovación general de los tejados, al derribo del campanario y construcción de uno nuevo en una esquina de la iglesia, sobre el coro, al arreglo del arco de la Capilla mayor de la iglesia y a la reconstrucción de parte del artesonado del mismo coro (Juliá Gómez, 1972, p. 56-57).

$Y$ a pesar de las importantes reformas patrocinadas por los duques de Santisteban y Medinaceli que tuvo el inmueble conventual a fines del siglo XVIII, durante la Guerra de la Independencia quedó bastante maltrecho y actualmente no existe.

El edificio estuvo ubicado concretamente en los límites que hoy marcan la calle Sagasta, la plaza del Artillero Cabot y la calle Lavaderos, y solo quedan unos cuantos vestigios en algunas casas de la última calle citada, como un artesonado del antiguo convento, además de parte del claustro, que se conserva en el Museo Arqueológico de la propia villa santistebeña.

\section{DISCUSIÓN Y CONCLUSIONES}

De la numerosa cartografía y planimetría histórica que custodia el Archivo de la Fundación Casa Ducal de Medinaceli, con casi un millar de piezas, hemos recopilado y tratado aquí de aquellas referidas a inmuebles ubicados en Santisteban del Puerto, ya desaparecidos, como eran las casas-palacio levantadas por quienes ejercieron el cargo y dignidad de Caudillos mayores del reino de Jaén en el cerro amesetado del castillo de San Esteban y en la plaza mayor de la propia villa, así como la cárcel del lugar y el convento de San Francisco.

Todos estos planos fueron trazados en el siglo XVIII, y de ellos se desprenden interesantes conclusiones.

Por un lado, esta planimetría denota la escasa presencia de los condes y duques de Santisteban en la villa cabecera de su principal estado jiennense durante las últimas centurias, pues las descripciones de ambas casas-palacio no dejan ver unas estancias "nobles" para acoger de forma habitual a estos señores. Se trata, más bien, de inmuebles dedicados a la administración señorial, habitados permanentemente por el alcalde mayor, en el caso del castillo, y por el contador mayor del estado, en el caso del palacio nuevo de abajo situado con fachada a la plaza Mayor. Ello no supone, sin embargo, que los condes y duques del lugar no pasaran entonces alguna temporada y pernoctaran en más de una ocasión en estos inmuebles.

La razón de esta ausencia habitual de los señores se nos antoja muy clara. Los Benavides, condes y luego duques de Santisteban del Puerto, vivieron preferentemente en la Corte a partir de la segunda mitad del siglo XVI ${ }^{35}$, teniendo como morada principal la "Casa Grande" que tenían frente a la madrileña iglesia del San Pedro el Viejo, con la plaza del mismo nombre de por medio, conectada a la calle del Nuncio desde la denominada Pretil de Santisteban (Sánchez González, 2015, p.109-11036), otro edificio igualmente demolido a fines del siglo XIX (Sánchez González, 2017a, p.316-318) como se desprende de la planimetría conservada en el propio Archivo Ducal ${ }^{37}$.

Todo hace indicar además que, cuando estos Benavides bajaban a sus estados del sur para pasar algunas estancias dedicados personalmente a la administración de sus dominios jiennenses, residían principalmente en el palacio que tenían en la cercana Castellar de Santisteban, un edificio de buena sillería del siglo XVI con portada de medio punto de estilo renacentista y los escudos de armas señoriales labrados en la clave, que había sido edificado sobre el antiguo castillo medieval del lugar (Sánchez González, 2015, p. 82 y 84). Aún queda en pie la torre del homenaje y el patio de armas de aquella antigua fortaleza, en un edificio rehabilitado que sirve de sede al Ayuntamiento de la localidad desde 1998. Junto a este "palacio ducal" se emplazaba, como hoy, la majestuosa Iglesia Colegial de Santiago, fundada en 1634 por el obispo Mendo de Benavides.

35. Al parecer, el primer Benavides que inicia la diáspora hacia la Corte es el VII Conde de Santisteban Francisco de Benavides y de la Cueva (1582-1640), residiendo en esta casa que debió ser adquirida por su madre, doña Leonor Dávila y Toledo ( ? -1642), a fines del siglo XVI o principios del XVII. Desde entonces, durante dos siglos, se convirtió en residencia habitual de la familia. Después se transformó en la Casa de Postas del duque de Santisteban (1742), obra de Gabriel González, y casa de viviendas a fines del siglo XIX.

36. Véase, además, ADM, Santisteban, leg. 28 nos 12-30.

37. ADM, Mapas y planos, nos 332-337. 
En el caso del antiguo convento franciscano de la villa de Santisteban del Puerto, esta planimetría demuestra, por su condición de ser patronazgo y panteón familiar de los condes y duques de Santisteban del Puerto, la acometida de unas reformas necesarias en el inmueble en el siglo XVIII ante la progresiva degradación en la que cayó con el paso de los siglos. Sin embargo, los efectos causados en el inmueble por la inmediata guerra de la Independencia, así como las repercusiones del proceso de exclaustración con la desamortización de mediados del mismo siglo XIX, determinaron la demolición del convento.

Un estudio más profundo de los inmuebles santistebeños aquí tratados, lamentablemente ya desaparecidos, en base a la documentación facilitada por nosotros despejarán dudas y clarificarán aspectos aún no del todo resueltos, lo que ya escapa a un trabajo de estas características.

No obstante, parece claro que aquí hemos conseguido nuestro objetivo de aclarar con precisión a qué palacios, de los dos que tuvieron los señores del lugar, se corresponden exactamente los planos palaciegos a los que nos hemos referido, a la vez que hemos aportado datos de la cárcel de Santisteban y del convento franciscano que tuvo la villa, de los que quedan escasos vestigios en nuestros días.

\section{FINANCIACIÓN}

Este trabajo es, en parte, resultado del proyecto de I+D de Excelencia HAR2013-41500-P: "La colección de Mapas, Planos y Dibujos del Archivo Ducal de Medinaceli: catalogación y estudio", financiado en su día por el Ministerio de Economía y Competitividad español, que fue dirigido por el propio autor de este estudio.

\section{REFERENCIAS}

Burgueño, J. (dir.). (2001). Atles de les viles, ciutats i territoris de Lleida. Lleida: Diputació Provincial - Col-legi d'Arquitectes de Catalunya, Demarcació de Lleida.

Burgueño, J. y Gras, M. (2014). Atles de la Catalunya senyorial: els ens locals en el canvi de règim (1800-1860). Barcelona: Institut Cartogràfic i Geològic de Catalunya; Rafael Dalmau.

Calatrava, J. y Ruiz Morales, M. (2005). Planos de Granada: cartografía urbana e imagen de la ciudad. Granada: Diputación Provincial de Granada.

Eslava Galán, J. (1999). Los castillos de Jaén. Granada: Ediciones Osuna.

Galera, M. (1998). Antoon van den Wijngaerde, pintor de ciudades y de hechos de armas en la Europa de los Quinientos. Barcelona: Institut Cartográfic de Catalunya.

Gámiz, A. (1999). Ciudades dibujadas a vista de pájaro o retratadas desde globo: hacia 1853. Revista de Historia y Teoría de la Arquitectura, 9, 170-180.

Gámiz, A. (2010). Las vistas de España del viajero David Roberts, pintor de paisajes y arquitecturas, hacia 1833. Revista EGA, 15, 54-65. https://doi.org/10.4995/ega.2010.992

Hardoy, J. (1991). Cartografía urbana y colonial de América Latina y el Caribe. Buenos Aires: Grupo Editorial Latinoamericano. Juliá Gómez, J. (1972). El convento de San Francisco de Santisteban del Puerto. Boletín del Instituto de Estudios Giennenses, 70-71, pp. 37-64. Recuperado de http://dialnet.unirioja.es/servlet/oaiart?codigo=2070167.

Kagan, R. (1986). Ciudades del Siglo de Oro. Las vistas españolas de Antón Van den Wyngaerde. Madrid: El Viso, 1986.

Kagan, R. (1992). Imágenes urbanas del mundo hispánico 1493-1780. Madrid: El Viso, 1992.

MacDonald, R. A. (1990). Espéculo. Texto jurídico atribuido al Rey de Castilla Don Alfonso X el Sabio. Edición, introducción y aparato crítico. New York.

Mercado Egea, J. (1973). La muy ilustre villa de Santisteban del Puerto. Madrid.

Mercado Egea, J. (1997). Santisteban del Puerto: Historia y Diplomática hasta finales del siglo XIV. Jaén.

Mexía, F. (1492). Nobiliario vero. Sevilla: Pedro Brun y Juan Gentil (ed. facs. Madrid: Ministerio de Educación y Ciencia, 1974). Ortega Vidal, J. (2000). Los planos históricos de la ciudad de Madrid y su fiabilidad topográfica. CT Catastro, 39, 65-85.

Paz y Mélia, A. (1915). Series de los más importantes documentos del Archivo y Biblioteca del Excmo. Sr. Duque de Medinaceli. I. Archivo. Madrid. 
Salazar de Mendoza, P. (1618). Origen de las dignidades seglares de Castilla y León. [Toledo edic. Madrid: Oficina de Don Benito Cano, 1794]. Recuperado de http://books.google.es/books?id=SlkaKDk-VegC\&lpg=PP1\&hl=es\&pg=PA161\#$\mathrm{v}=$ onepage\&q\&f=true

Sánchez-Arcilla Bernal, J. (2004). Las Siete Partidas. Alfonso X el Sabio: El libro del fuero de las leyes. Madrid: Editorial Reus.

Sánchez González, A. (1997). El Archivo General de la Casa Ducal de Medinaceli: un modelo de aportación de los Archivos Nobiliarios españoles a la ciencia Archivística. En Il futuro della memoria. Atti del Convegno Internazionale di studi sugli Archivi di famiglie e di persone, Pubblicazioni degli Archivi di Stato SAGGI, 45. Roma, I, 347-367.

Sánchez González, A. (2009). La colección de Privilegios Rodados originales del Archivo Ducal de Medinaceli (1175-1458). Lope de Barrientos. Seminario de Cultura, 2, 217-279.

Sánchez González, A. (2015). El Archivo de los Caudillos del reino de Jaén (Casa de Santisteban del Puerto). Jaén: Instituto de Estudios Giennenses - Diputación Provincial de Jaén.

Sánchez González, A. (2016). El señorío y marquesado de Solera. Historia, Archivo y Documentos. Granada: Editorial Atrio.

Sánchez González, A. (ed.) (2017a). El arte de la representación del espacio: mapas y planos de la colección Medinaceli. Huelva: Universidad de Huelva.

Sánchez González, A. (2017b). Los mapas y planos del Archivo Ducal de Medinaceli, una colección iconográfica singular: origen, procedencias y generalidades. En A. Sánchez (ed.) El arte de la representación del espacio: mapas y planos de la colección Medinaceli, pp. 17-38. Huelva: Universidad de Huelva.

Sánchez Rivero, Á. \& Mariutti, Á. (1933). Viaje de Cosme de Médicis por España y Portugal (1668-1669). Madrid: Sucesores de Rivadeneyra S.A. (carpeta de láminas).

Toral y Fernández de Peñaranda, E. (1984). El Caudillazgo Mayor del Obispado de Jaén y la Casa Condal de Santisteban del Puerto. Boletín del Instituto de Estudios Giennenses, 118, pp. 9-43.

Vidania, D. V. de (1696). Memorial de los servicios de la Casa de Benavides. Nápoles: Por Dominico Antonio Parrino y Miguel Luis Mucio.

Vázquez Campos, B. (2000). Sobre los orígenes del Adelantamiento de Andalucía. Historia. Instituciones. Documentos, 27, 333-373.

Vázquez Campos, B. (2006). Los Adelantados mayores de la Frontera o Andalucía (siglos XIII-XIV). Sevilla: Diputación Provincial. 